\title{
Color and rehydration characteristics of natural red colorant of foam mat dried Hibiscus sabdariffa L. Powder
}

\begin{abstract}
This research was aimed to develop natural red colorant powder from Hibiscus sabdariffa L. fruit using foam mat drying. Egg albumen (EA) at different concentrations (5-20\% w/w) was used as a foaming agent, and samples were whipped for 10 minutes. The samples were hot air dried at $50^{\circ} \mathrm{C}$ for 6 hours. Effect of EA concentration on the foam properties and physicochemical properties of the powders were analyzed. In addition, the effect of temperatures $\left(10-80^{\circ} \mathrm{C}\right)$ on color and rehydration characteristics of rehydrated powders were studied. The result showed that $15 \%$ EA concentration of foam mat dried H. sabdariffa L. powder has good quality characteristics.
\end{abstract}

Keyword: Egg albumen; Foam mat drying; Red color; Rehydration; Natural colorant; Roselle 